\title{
An exploration of the experiences of adolescents living with HIV
}

\author{
L.L. Pienaar ${ }^{\mathrm{a}}$ and M.J. Visser ${ }^{\mathrm{b}}$ \\ ${ }^{a}$ Directorate of Student Development and Support, Tshwane University of Technology, Pretoria, \\ South Africa \\ ${ }^{b}$ Department of Psychology, University of Pretoria, Pretoria, South Africa
}

\begin{abstract}
This research endeavours to voice the told and untold stories of adolescents who have been living with HIV and have to adhere to chronic disease management at the Kalafong Hospital's Paediatric HIV Clinic in Pretoria, South Africa. Six adolescents who attend the clinic regularly were interviewed using a social constructionist narrative approach. Data was collected by means of two semi-structured individual interviews with each participant using expressive art (drawings and poetry). Collaborative exploration between the researcher and each adolescent made it possible to coconstruct the meanings that the adolescents attach to their stories of HIV, which inform their identities. The three-dimensional space approach by Clandinin and Connelly (2000) was used to interpret their stories according to the aspects of temporality, context and identities. Adolescents constructed multiple identities in the various contexts they described, though HIV formed a central part of these identities. They attributed different meanings to HIV, such as sameness or difference. The stories raised awareness of the challenges and dilemmas they are faced with, such as disclosure, adherence to treatment, disease management and lack of support. The adolescents identified lack of communication and impersonal interactions with health care providers as barriers to disease management. They had conflicting ideas about antiretroviral therapy and the restrictions it placed on their lives. Based on our study it is recommended that clinics should provide ongoing support to HIV-infected adolescents to assist them in accepting the consequences of HIV infection and to provide assistance not only with disclosure of their status to friends, family and partners, but also with adherence to treatment. The results can enhance health care providers' understanding of the real-life situation of adolescents attending the clinic for disease management.
\end{abstract}

Keywords: HIV/AIDS, chronic disease management, adolescence identity development, social constructionism, narrative approach 
According to the Joint United Nations Programme on HIV/AIDS (UNAIDS, 2009), South Africa is home to the world's largest population of people living with HIV. Before the introduction of antiretroviral therapy (ART), the mortality rate was high in HIV-positive infants and children, due to the rapid progression of the disease. The national roll-out of ART in 2004 has increased the life span of these groups, making it possible for them to reach adolescence and adulthood (Anderson \& Seedat, 2009). However, the adolescent population that is currently living with HIV faces unique challenges that affect their developing identities and disease management.

Adolescence is a developmental stage that focuses on unique developmental tasks such as the establishment of a sense of identity (Goossens, 2006). Adolescents are known to have an increased capacity to understand and question values, attitudes and beliefs (Thom \& Coetzee, 2004). They also have an enhanced need for independence and for acceptance by their peer group. Adolescents living with HIV may experience numerous additional challenges. They do not want to be perceived as different from their peers. Due to their increased desire to express independence, they may tend to distrust or reject figures of authority, which can contribute to their being attracted to alternative or unconventional sources of information. This may result in risk behaviour and jeopardise their adherence to treatment (Thom, 2007), which has implications for the health care provider who attends to adolescents living with HIV.

The quality of health care for those living with a chronic illness in South Africa is constrained by challenges such as increased patient numbers, staff shortages and limited patient resources. This can result in poor communication and hamper the clear or accurate sharing of information with the patient, which can in turn have a negative effect on the patient's cooperation and adherence to treatment (Goudge, Gilson, Russell, Gumede \& Mills, 2009). Seeing that HIV-infected adolescents' experiences in the medical context come to inform their identity, their relationship with the health care provider is of utmost importance. It 
is therefore essential that the health care provider understands the experiences of these adolescents in an effort to create an environment that encourages the adolescent to establish and maintain a constructive relationship with HIV.

The Kalafong Hospital's Paediatric HIV Clinic was established specifically to attend to HIV-positive infants, children and adolescents in the Pretoria area. Because of the availability of ART, the adolescent population attending this clinic is growing steadily. In November 2008, 43 adolescents regularly attended the clinic for disease management (Vlug, Feucht \& Kruger, 2008), compared to 138 in 2011. The aim of this study is to voice the told and untold stories of these adolescents who live with HIV and receive assistance with chronic disease management at the Kalafong clinic, so as to gain an understanding of the meanings they attribute to their experiences of HIV and the challenges and dilemmas they are faced with.

\section{Method}

\section{Study design and sample}

The study was conducted using a qualitative social constructionist narrative approach. A nonprobability, purposive sampling method was used to identify participants who complied with the following three criteria: being an adolescent attending the clinic on a regular basis for ART and disease management; being in the age group 12-18 years, and being fluent in English (mostly as a second or third language). The attending clinic doctor obtained consent from possible participants to disclose their information to the researcher. The researcher then individually approached the identified adolescents when they attended the clinic, explained the research and invited them to participate in the study. Adolescent assent and parent or caregiver consent were finalised before the data collection commenced. Three female and three male adolescents participated voluntarily in the study. 


\section{Data collection}

Data was collected by means of semi-structured interviews. Expressive art (drawings and poetry) was used to facilitate storytelling and communication. Two individual interviews were scheduled with each participant. The first interview served to collect stories and art work. The interview commenced by establishing whether the adolescent was aware of his/her HIV status. This was explored by means of inquiring into the adolescent's reasons for attending the clinic. The term "illness" was used and no reference was made to "HIV", unless the adolescent introduced it during the interview. This was done not to indirectly disclose their status to those who were not aware of it. There was only one participant who did not know her status.

During the first interview, two main themes were introduced. The first theme explored the adolescent's knowledge of and relationship with HIV. The participant was asked to draw a picture of him/herself in relation to HIV or illness. The second theme explored the adolescent's experiences of disease management at home, at school and at the clinic and he/she was asked to draw a picture of him/herself at the clinic. The second interview served as a follow-up debriefing session where the re-constructed stories were discussed. A co-researcher who is fluent in Tswana assisted the researcher in three of the interviews to allow adolescents to tell their stories in their vernacular.

\section{Analysis}

Clandinin and Connelly’s (2000) three-dimensional space approach was used as method of data analysis. The stories gathered during the interviews were transcribed verbatim from the audio recordings (for which parents and participants gave their consent). The transcripts were analysed for the elements of personal and social interaction, continuity or time, and situation or place. Hereafter the stories were re-written and placed in chronological sequence (Ollerenshaw 
\& Creswell, 2002). The drawings and poetry were used to situate and understand the adolescents’ stories.

The re-storied accounts were interpreted according to the context, the identities and the aspects of temporality found in the stories. The adolescents' stories were situated in the family and cultural, the school and social, and the medical contexts. Through the description of their experiences and interactions with people in these contexts, multiple identities were constructed (Crossley, 2000; Scheibe, 1986).

The research adhered to strict ethical principles approved by the Ethics Committee of the Faculty of Humanities at the University of Pretoria.

\section{Results}

\section{Stories of the adolescents}

In all the stories, pseudo names were used to protect the identities of the adolescents involved.

Mary is a 13-year-old girl who stays with her grandmother and extended family. She does not know of her HIV status, but describes herself as a girl who is ill, based on her experience that her body hurts. She therefore takes medication in order to be healthy. She describes the hospital as a place where they examine her body and she gets medication to help her feel better. She does not see herself as different from other children because she observes that some other children from school are also ill and take medication to stay healthy.

Petrus is a 14-year-old boy who stays with his uncle and cousins. He found out that he was HIV positive three months before the interview when he went to the hospital because he was ill. He was shocked and cried. However, he soon realised that "if he continues to cry, he will cry for the rest of his life". He decided to accept his status as a normal part of life. Knowledge about his HIV status therefore did not change his self-perception or interaction with others. He constructed his identity as a normal boy. No one except his uncle is aware of 
his HIV status. His uncle gave him the option to disclose his status to others when he is older or when he feels ready to do so. He did not reveal his patient identity at school. He believes that he is not different from other children, therefore he participates in athletics and friendships like his peers. Despite his peers' belief that HIV kills people, Petrus believes that one can live with HIV.

Sera is a 14-year-old girl who lives with her aunt and uncle and two cousins since her parents passed away. In this family they never speak about her parents or about HIV, although her status is known to them. Her patient identity was established more than five years ago after she had been constantly ill. She was then informed about her HIV status. She presents herself as a realist who is open about and easily expresses her opinions. She explains that she accepts living with HIV because she has no other choice. Although Sera's family is aware of her status, she finds it difficult to share her feelings with them. Her friends are important to her but they are not aware of her status. She would eventually like to disclose it to them but feels that they would be shocked as her peers tend to believe that HIV is a disease that only affects "other" people.

Dan is a 15-year-old boy who lives with members of his extended family who are aware of his HIV status. He found out that he was HIV positive one year ago when his CD4 count was dangerously low and he lost weight. He was sad when he became aware of his status. After he started using ART, his CD4 count increased and he gained weight. Dan describes himself as a boy that looks happy. He sees medication as something that does not cure, but makes a person feel better. He knows that he will always be HIV positive and sees it as part of his identity as a patient (Illustration 1). For Dan, HIV is a disease that is painful, has no cure and kills many people. He associates the medical context with sadness, death and dying, and wishes that illness and hospitals did not exist - he wanted to escape from his patient 
identity. On the other hand, he realises that the hospital helps him and other people to become better, which makes him happy. He disclosed his status to his school teachers. They support him and send him home when he is sick.

\section{Illustration 1 Dan's drawing}
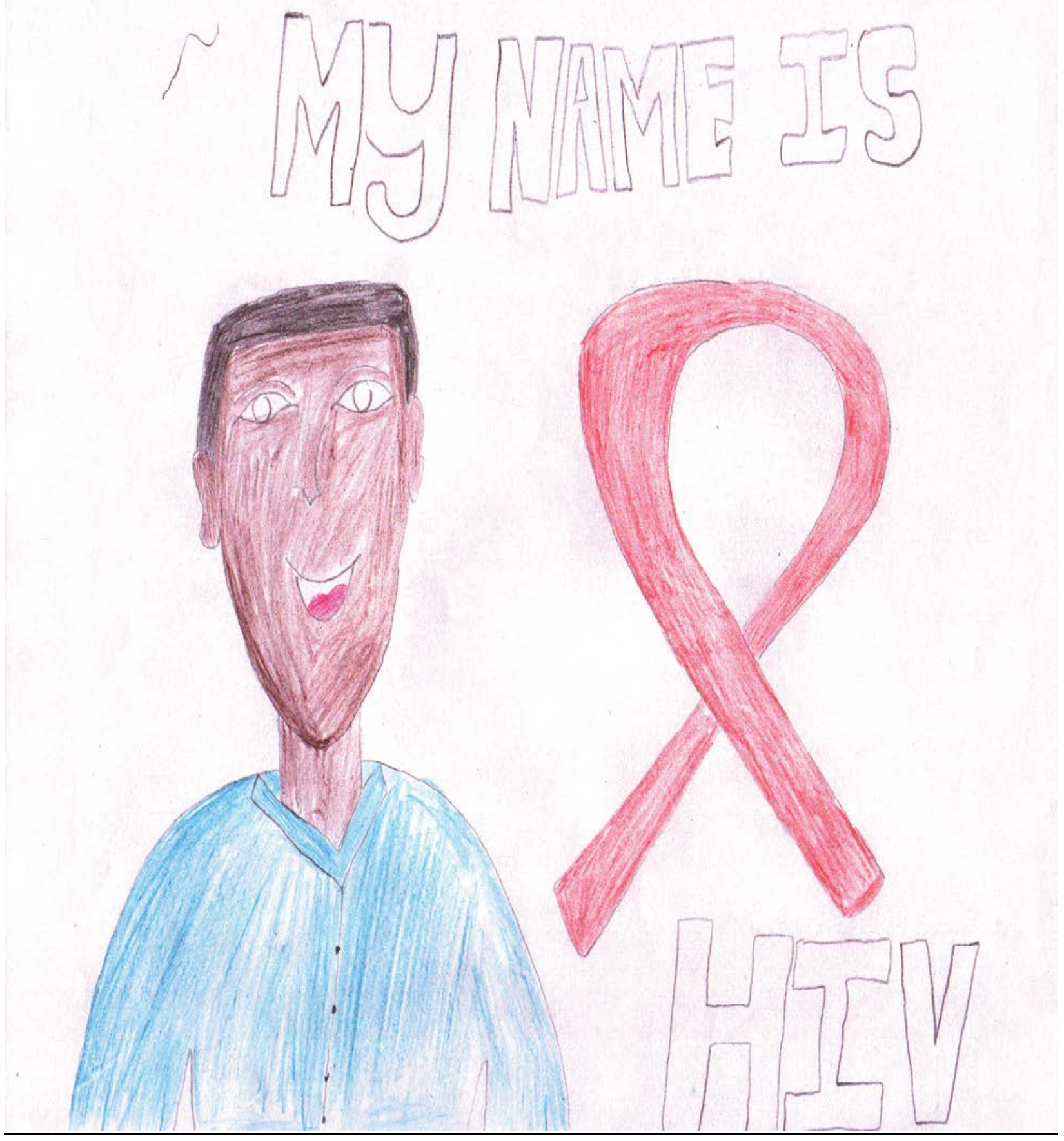
Illustration 2 Julie's drawing

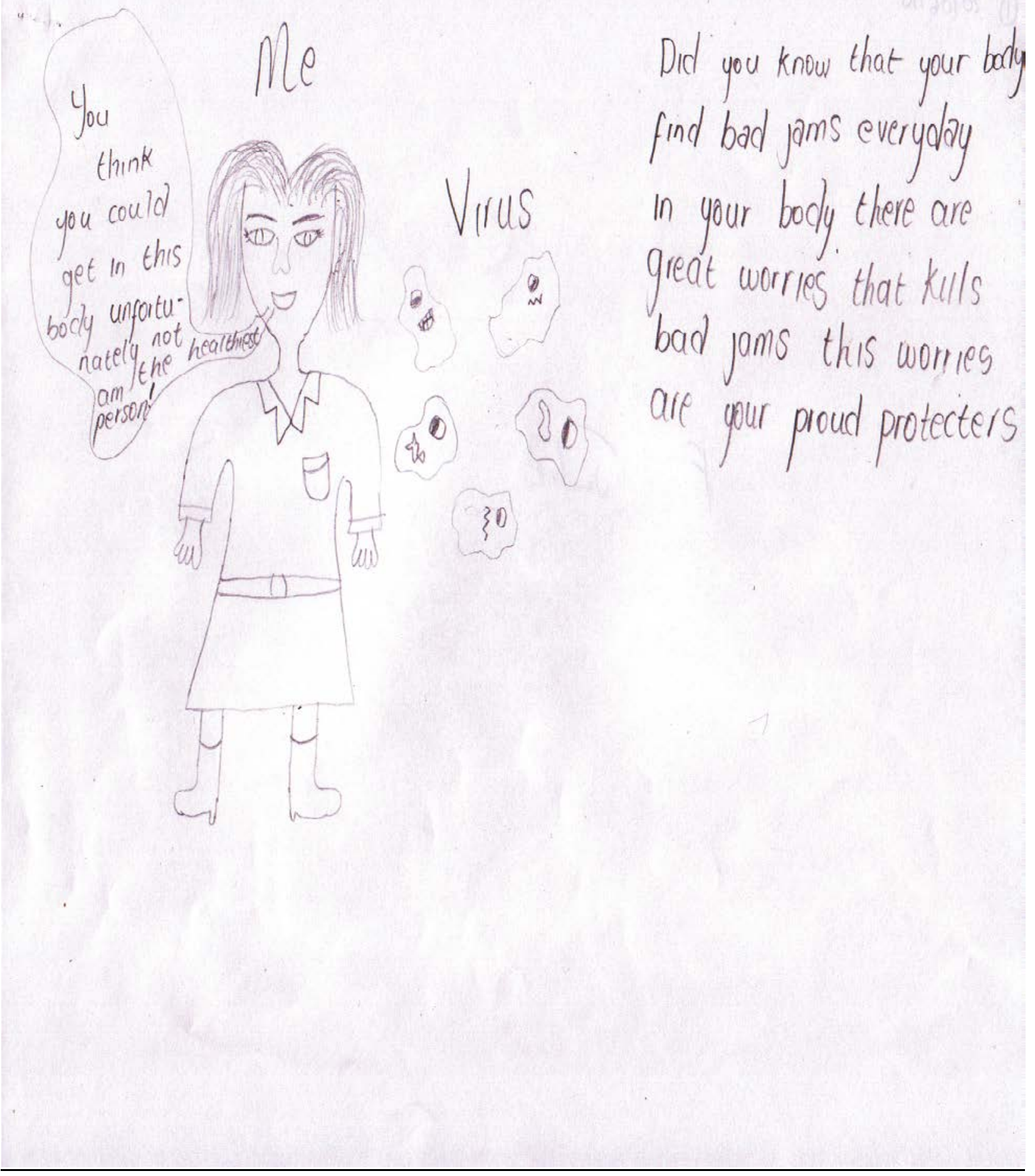

Julie is a 16-year-old girl living with her aunt and grandmother. Her mother passed away when she was one year old. Her extended family supports her and educates her about 
HIV. She found out about her HIV status approximately five years ago. Before that she had been chronically ill. She was angry about the diagnosis and wanted to know how she became infected. She understands her relationship with HIV through a metaphor of war. She is engaged in a battle between fighting HIV and surrendering to its consequences. She explains that HIV is bad and dangerous, because it attacks her body’s white cells, which makes her body weak. She takes medication daily as it helps her immune cells to be healthy to fight and kill HIV. When she felts ill, she felt hopeless and fearful and surrendered to HIV; however, she feels better and optimistic now and describes herself as a conquering patient. Julie dreams about being a mother and a grandmother and desires a long life - in contrast to her fear of dying. She currently feels strong and proud of her achievement to conqueror HIV (Illustration 2). She portrays herself as a self-sufficient, healthy and strong young lady who is determined to stay positive and fight HIV. Julie has, however, not been able to share these experiences with her friends at school, since she is afraid of their rejection. The teachers and friends think that she has asthma. Julie describes herself as an expressive girl who likes to sing, act and write poetry. Through this expressive identity she dreams of becoming famous in the future. Then she would feel proud to tell people of her HIV status.

Bongi is a 17-year-old boy who lives with his grandparents who support him. He was diagnosed five years ago. Initially he was angry with both his mother and father because of the infection. He experiences conflict between wanting to be a normal person and being different. Living with HIV and having to adhere to disease management has confronted him with numerous challenges. He feels trapped because he has to organise his life around taking his medication and cannot go to sleep at any time or do what he wants to, like other children. The use of medication makes him feel as if he is not human, as he has to rely on the medication to keep him alive. He wishes he could forget about his medication for at least a day to feel like a 
Illustration 3 Bongi's drawing

1

HOPE

(But, are we near it)

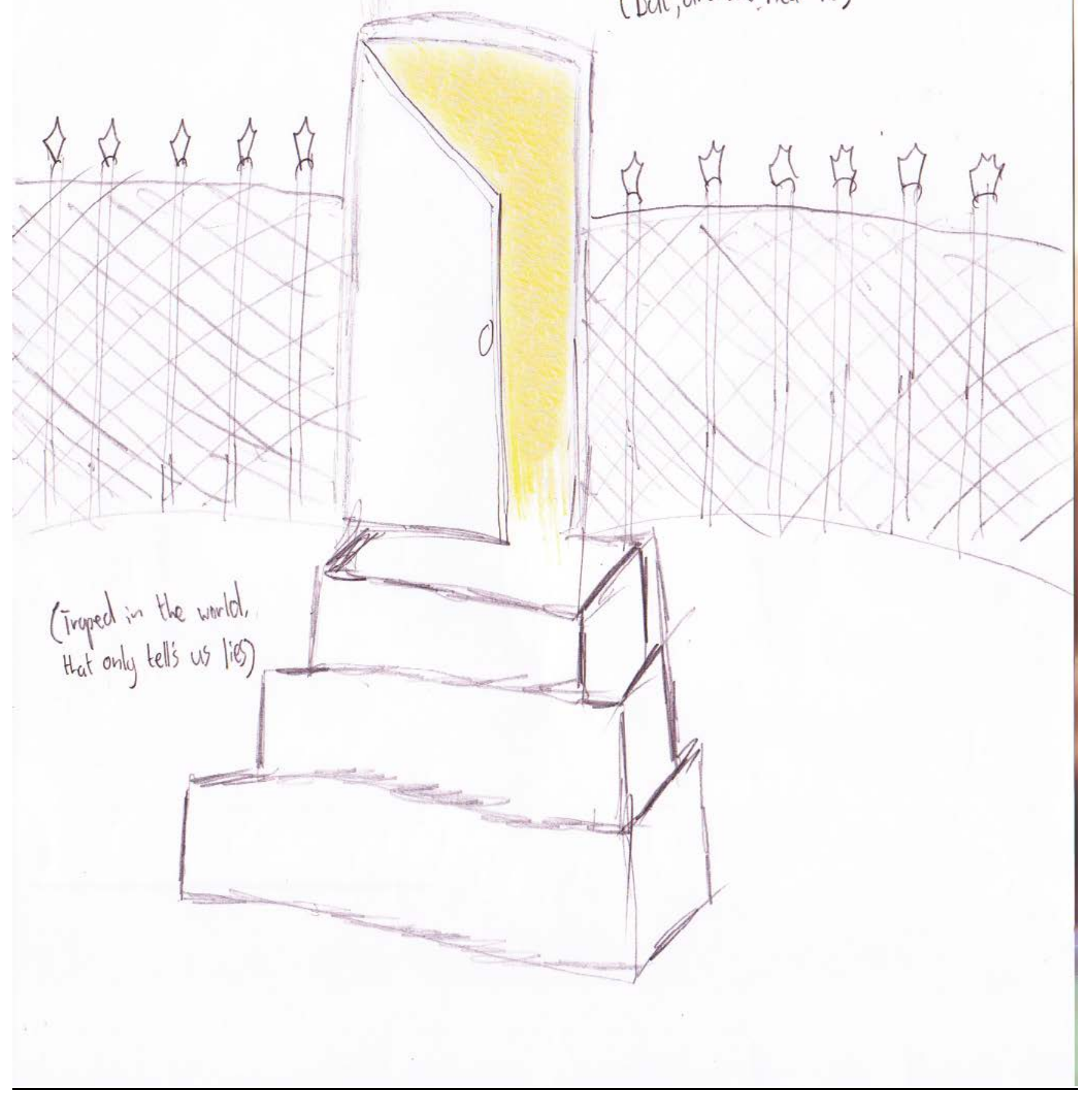


normal boy. He cannot sleep over at friends or go on trips because he may accidentally

disclose his status. He wants to disclose his status and feels that his friends will accept him, but his grandmother fears that people will burn their house if they find out his status. Due to respect for his grandmother's wishes, he has decided not to disclose his status yet. Bongi has a girlfriend but cannot tell his grandmother about her, because his grandmother warned him not to have a girlfriend. He feels trapped in a world that tells lies about HIV. He doubts if there really will be a cure that could give him hope (Illustration 3). Despite these limitations, Bongi takes part in sport and has many friends. For Bongi one positive aspect about having HIV is that it keeps him from engaging in risk behaviour such as using drugs.

\section{Common themes}

Although the individual stories of the adolescents differed, several similar themes could be identified.

\section{Awareness of HIV status}

All the adolescents except one were aware of their HIV status. Most of them had been informed of their HIV status during early adolescence while being treated for serious illness. Although this was a sad and traumatic experience for most of them, they accepted their status as part of their identities thereafter. They described the disclosure as a once-off event resulting in chronic disease management.

\section{Disclosure to others}

All the family members who lived with the adolescents were aware of their status, except for Petrus whose uncle was the only one who knew. Only one adolescent disclosed his status to someone outside the immediate family, namely to his teachers, so that they would know he was at the hospital if he was not attending school. All of them were considering disclosure to others in the future but were still contemplating the consequences thereof. They were afraid of 
possibly being rejected by others. Fear and stigma thus continue to bring about difficult

psychosocial circumstances to those infected and affected by HIV (Anderson \& Seedat, 2009).

Normality vs. difference

All of the adolescents battled with the conflict between being normal and being different. All of them tried to live a normal life by having friends and participating in sport, and all had plans for the future. It seems that the older adolescents experienced greater limitations in living with the secret of their HIV status than did the younger ones, which served to intensify this conflict. Support

All of the adolescents stayed with extended family since their parents had passed away. One of the adolescents expressed his anger with his parents and blamed them for his infection. The adolescents received support from these relatives in living with HIV at home, mostly in the form of physical support and assistance with adherence to ART. However, most of the adolescents assumed primary responsibility for taking their medication. Emotional support seemed to be limited though, as they could not discussed their experiences with family members and none of them had yet dared to disclose their status to their peer group.

The interview that was conducted as part of the research provided the adolescents the opportunity to tell their stories of living with HIV and to share some of the challenges they could not share with others. It was clear from our research that health care services should provide essential and ongoing support for adolescents to deal with the emotional consequences of HIV (Thom, 2009; Anderson \& Seedat, 2009).

\section{Disease management}

Most of the adolescents described disease management as a generally positive experience. They described clinic visits as a routine that takes a long time and admitted that they did not always know why certain procedures such as pricking fingers were performed. Yet they valued 
personal counselling and identified formal and impersonal interactions with health care providers and a lack of communication as barriers to disease management. These barriers were also identified by Goudge et al. (2009) and Ayres et al. (2006) as obstacles to health care.

\section{ART and adherence}

Strict adherence to ART is an enormous responsibility and obligation for adolescents and forms an important part of their daily lives. Three of the six participants have been using ART daily for approximately five years. They had conflicting ideas about the role of ART in their lives. Although ART helped them to feel better, two adolescents experienced negative side effects and especially Bongi expressed frustration at taking medication as it limited his life as a teenager.

\section{Conclusion}

The stories of the six adolescents who attended the Kalafong Paediatric HIV Clinic for disease management and ART were told using the narrative approach. The exploration of their stories brought about an awareness of the challenges they are experiencing. It was found that their patient identity largely shapes their experiences and ultimately informs the development of all aspects of their identity.

The results of the study should therefore contribute towards creating a greater sensitivity among health care providers towards the experiences of adolescents who have to abide by chronic disease management. Since young people in this age group already have to cope with unique developmental tasks, the recommendation is that ongoing support services should be made available to HIV-infected adolescents as this would assist them in understanding the consequences of the disease in their lives. They need support with adherence to treatment; disclosure of their status to friends, family and partners; finding ways of dealing with potential stigma; and with constructively integrating HIV into their identities and 
interpersonal relationships. Ongoing support will assist the developing adolescent to cope with the questions and difficulties associated with growing up (Thom, 2007).

The current research was limited by the small number of adolescents who participated. More stories of adolescents living with HIV should be told. Future research should strive to tell the stories of older adolescents, as the group that participated in this research comprised mainly younger adolescents.

\section{Acknowledgements}

The researchers would like to thank the adolescents who participated and the Kalafong Hospital's Paediatric HIV Clinic for the opportunity to share and journey alongside them in their experiences of HIV.

\section{References}

Anderson, L. S., \& Seedat, S. (2009). Mental health services for HIV/AIDS patients are long overdue. South African Medical Journal, 99(11), 796.

Ayres, J. R. C. M., Paiva, V., Franca, I., Gravato, N., Lacerda, R., Negra, M. D., et al. (2006). Multisectorial responses to HIV/AIDS, vulnerability, human rights, and comprehensive health care needs of young people living with HIV/AIDS. American Journal of Public Health, 96(6), 1001-1006.

Clandinin, D. J., \& Connelly, F. M. (2000). Narrative inquiry. Experience and story in qualitative research. San Francisco: Jossey-Bass.

Crossley, M. L. (2000). Introducing narrative psychology. Self, trauma and the construction of meaning. Philadelphia: Open University Press.

Goossens, L. (2006). Adolescent development: Putting Europe on the map. In S. Jackson \& L. Goossens (Eds.), Handbook of adolescent development (pp. 1-10). New York: Psychology Press.

Goudge, J., Gilson, L., Russell, S., Gumede, T., \& Mills, A. (2009). Affordability, availability and acceptability barriers to health care for the chronically ill: Longitudinal case studies from South Africa. BMC Health Services Research, 9, 75-93. 
Ollerenshaw, J., \& Creswell, J. W. (2002). Narrative research: A comparison of two restorying data analysis approaches. Qualitative Inquiry, 8(3), 329-347.

Scheibe, K. E. (1986). Self-narratives and adventure. In T. R. Sarbin (Ed.), Narrative psychology. The storied nature of human conduct. New York: Praeger.

Thom, D. P., \& Coetzee, C. H. (2004). Identity development of South African adolescents in a democratic society. Society in Transition, 35(1), 183-193.

Thom, R. (2007). Psychiatric aspects of HIV/AIDS in adolescents. Adolescent Psychiatry, 25(5), 228-230.

Thom, R. (2009). Clinical overview. Common mental disorders in people living with HIV/AIDS. The South African Journal of HIV Medicine, 8-13.

UNAIDS (2009). AIDS epidemic update. Retrieved on 16 February 2009 from http://data.unaids.org/pub/Report/2009/JC1700_Epi_Update_2009.

Vlug, M. S., Feucht, U. D., \& Kruger, M. (2008). Establishing an adolescent antiretroviral therapy clinic at Kalafong hospital in Pretoria: Lessons learnt. Paper at $2^{\text {nd }}$ Priorities in Child Health Conference, 4-5 December.

White, M., \& Epston, D. (1990). Narrative means to therapeutic ends. New York: Norton. 